\title{
Kepemimpinan Inspirational Motivation Kepala Sekolah Dalam Pembelajaran Sains Robotika Di SIIA Averos Kota Sorong
}

\author{
Sri Akidah \\ Guru Madrasah Tsanawiyah Negeri Kota Sorong \\ sri.akidah28@gmail.com
}

\begin{abstract}
This paper outlines the Inspirational Motivation Leadership of The Principals in learning Robotics at Averos Sorong City High School. Robotics is an excellent subject at Averos High School. In addition, Robotics Science is also an extracurricular activity for Averos high school students. Many achievements have been reached by Averos High School in robotics including the winner of the science olympiad competition, and winning the championship at the national level and some are sent to compete in the other country. This is inseparable from the leadership of the Principal of Averos High School. Therefore, it is interesting to discuss the Inspirational Motivation Leadership of Sorong City High School Senior High School. The results of this study are Robotics Science is a local subject in Averos Sorong City High School. Robotic Science in Averos High School is divided into two groups, namely robotics as a subject and robotics as club. Robotics Science Learning is given to all Class $X$ and Class XI students. The aim of learning robotics is to improve the quality of Averos high school students. So, when they graduate from Averos they will have competitiveness
\end{abstract}


in the development of science and technology. And the Principal Inspirational Motivation Leadership in Robotics Science Learning is demonstrated by caring for teachers, staff and students, involving everyone in the organization. Giving appreciation, making sure that the subject is fun, showing real trust, and listening to subordinates. While the output of robotics science was made students capable of creating Arduino Soccer-Transforter Robot in 2013, Drone in 2013, Robot Linetracer Analog 12 Sensors in 2014, Robot Wall Follower 2014, Analog Transforter Robot 2017, Miniature Wireless Bluetooth Based Home 2018, Alingu in 2018, Seven Segments in 2018, and Bluetooth Pairing Robot.

Keywords: Principal Leadership, Inspirational Motivation, Robotic.

Abstrak: Tulisan ini menguraikan tentang Kepemimpinan Inspirational Motivation Kepala Sekolah dalam pembelajaran Sains Robotika di SMA Averos Kota Sorong. Sains Robotika merupakan mata pelajaran unggulan di SMA Averos. Selain mata pelajaran, Sains Robotika juga menjadi kegiatan ekstrakurikuler bagi siswa SMA Averos. Banyak prestasi yang telah diraih oleh SMA Averos dalam robotik, diantaranya adalah juara lomba olimpiade sains, dan bisa meraih juara di tingkat nasional dan ada juga yang dikirim bertanding ke luar negeri. Hal tersebut tidak terlepas dari kepemimpinan Kepala SMA Averos Kota Sorong. Olehnya itu, Menarik untuk dibahas Kepemimpinan Inspirational Motivation Kepala SMA Averos Kota Sorong. Hasil penelitian ini adalah Sains Robotika merupakan mata pelajaran muatan lokal (mulok) di SMA Averos Kota Sorong. Sains Robotik di SMA Averos Kota Sorong terbagi dua, yaitu robotika sebagai mata pelajaran (mapel) dan robotika club. Pembelajaran Sains robotika diberikan kepada seluruh siswa Kelas X dan Kelas XI. Tujuan pembelajaran sains robotika adalah adalah untuk meningkatkan kualitas peserta didik SMA Averos agar ketika lulus kelak memiliki daya saing di era yang menitikberatkan perkembangan sains dan teknologi. Dan Kepemimpinan Inspirational Motivation Kepala Sekolah dalam Pembelajaran Sains Robotika di SMA Averos Kota Sorong ditunjukkan dengan kepedulian terhadap guru, staf dan siswa, melibatkan semua orang dalam organisasi, memberi penghargaan, memastikan pekerjaan itu menyenangkan, 
menunjukkan kepercayaan nyata, dan mendengarkan bawahan. Sedangkan Output pembelajaran sains robotika di SMA Averos Kota Sorong adalah siswa mampu menciptakan Robot SoccerTransforter Arduino tahun 2013, Drone tahun 2013, Robot Linetracer Analog 12 Sensor tahun 2014, Robot Wall Follower 2014, Robot Transforter Analog 2017, Miniatur Rumah Berbasis Wireless Bluetooth tahun 2018, Alingu tahun 2018, Seven Segmen tahun 2018, dan Robot Pairing Bluetooth.

Kata Kunci: Kepemimpinan Kepala Sekolah, Inspirational Motivation, Robotik.

\section{Pendahuluan}

Gaya yang ditampilkan oleh sosok pemimpin atau pola perilaku yang ditampilkannya dalam memimpin merupakan salah satu aspek yang menunjang keberhasilan sebuah institusi pendidikan. Secara umum, terdapat dua gaya kepemimpinan yaitu gaya dengan orientasi tugas (task oriented), dan gaya orientasi pada anggota (employee-oriented). Dalam perkembangannya seiring dengan perubahan sosial, terdapat tiga gaya kepemimpinan yaitu gaya kepemimpinan transaksional, kepemimpinan transformasional, dan kepemimpinan visioner. ${ }^{1}$

Kepemimpinan transformasional adalah pemimpin yang mempunyai kekuatan untuk mempengaruhi bawahan dengan cara-cara tertentu. Dengan penerapan kepemimpinan transformasional, bawahan akan merasa dipercaya, dihargai, loyal dan respek kepada pimpinannya. ${ }^{2}$ Dan kepemimpinan transaksional adalah pemimpin yang merujuk ke kumpulan model kepemimpinan yang berfokus pada pertukaran yang terjadi antara pemimpin dan pengikutnya. Dimensi pertukaran dari

1 Shalahuddin, Karakteristik Kepemimpinan Transformasional, Al-Fikrah: Jurnal Kependidikan Islam, IAIN Sulthan Thaha Saifuddin, 2015, 45.

2 I. Hay, Transformational Leadersiship: Characteristics and Criticism. School of Geography, Population and Enviromental Management Flinders University. Retrieved September 2016, from http://www.leadingtoday.org/weleadinlearning/ transformationalleadership.htm. 
kepemimpinan transaksional bersifat sangat umum dan bisa diamati pada banyak tingkatan di seluruh jenis organisasi. ${ }^{3}$

Kepemimpinan transformasional pertama kali dicetuskan oleh Downton. Hal itu mucul sebagai pendekatan penting untuk kepemimpinan, dimulai dengan karya klasik oleh sosiolog politis, James MacGregor Burns yang bertajuk Leadership. Di dalam karyanya, Burns berupaya menghubungkan peran kepemimpinan dan pengikut. Menurutnya, pemimpin sebagai orang yang meningkatkan motif pengikut untuk bisa mencapai tujuan pemimpin dan pengikut secara lebih baik. ${ }^{4}$

Di pertengahan tahun 1980-an, Bass menyediakan versi kepemimpinan tranformasional yang lebih luas dan telah diperbaiki, tetapi tidak secara penuh konsisten dengan karya awal Burns dan House. Di dalam pendekatan ini, Bass memperluas karya Burns dengan lebih banyak memberi perhatian pada kebutuhan pengikut daripada kebutuhan pemimpin. Bass memperluas karya House dengan memberi lebih banyak perhatian pada elemen emosional dan sumber karisma serta memberi saran bahwa karisma itu penting tapi bukan kondisi yang memadai untuk kepemimpinan transformasional. ${ }^{5}$

Bass menyatakan bahwa kepemimpinan transformasional memotivasi pengikut untuk melakukan lebih dari yang diharapkan dengan cara: Pertama, meningkatkan tingkat pemahaman pengikut akan kegunaan dan nilai dari tujuan yang rinci dan ideal. Kedua, membuat pengikut mengalahkan kepentingan sendiri demi tim atau organisasi. Ketiga, menggerakkan pengikut untuk memenuhi kebutuhan tingkatan yang lebih tinggi. ${ }^{6}$

Esensi kepemimpinan transformatif adalah mengubah potensi menjadi energi nyata, mengubah potensi institusi menjadi energi untuk meningkatkan mutu proses dan hasil belajar. Adapun indikator kepemimpinan transformasional yaitu: pembaharu, memberi teladan,

3 Peter G. Northouse, Kepemimpinan: Teori dan Praktik (Cet. II; Jakarta: PT. Indeks, 2016), 176.

4 Ibid.

5 Ibid., h. 179.

6 Ibid. 
mendorong kinerja bawahan, mengharmoniskan lingkungan kerja, memberdayakan bawahan, bertindak atas sistem nilai, meningkatkan kemampuan terus menerus, dan mampu menghadapi situasi yang rumit. ${ }^{7}$ Dan karakteristik kepemimpinan transformasional menurut Avolio dkk adalah sebagai idealized influence (or charismatic influence), inspirational motivation, intellectual stimulation, dan individualized consideration. ${ }^{8}$ Berikut penjelasan 4 karakter kepemimpinan tersebut:

1. Pengaruh ideal (idealized influence), merupakan komponen emosional dari kepemimpinan. Pengaruh ideal mendeskripsikan pemimpin yang bertindak sebagai teladan yang kuat bagi pengikut. Pengikut menghubungkan dirinya dengan pemimpin ini dan sangat ingin menirukan mereka. Pemimpin ini biasanya memiliki standar yang sangat tinggi akan moral dan perilaku yang etis, serta bisa diandalkan untuk melakukan hal yang benar. Mereka sangat dihargai oleh pengikut yang biasanya sangat percaya kepada mereka. Pengaruh ideal dapat diukur pada dua komponen, yaitu komponen yang merujuk pada pengakuan pengikut kepada pemimpin yang didasarkan pada persepsi yang mereka miliki atas pemimpin mereka, dan komponen perilaku yang merujuk pada observasi pengikut akan perilaku pemimpin.

2. Motivasi yang menginspirasi (inspirational motivation), menggambarkan pemimpin yang mengkomunikasikan harapan tinggi kepada pengikut, menginspirasi mereka melalui motivasi untuk menjadi setia dan menjadi bagian dari visi bersama dalam organisasi. Pada praktiknya, pemimpin menggunakan simbol dan daya tarik emosional untuk memfokuskan upaya anggota kelompok guna mencapai lebih daripada yang mereka lakukan untuk kepentingan pribadi mereka. Semangat tim ditingkatkan oleh jenis kepemimpinan ini.

3. Rangsangan intelektual (intellectual stimulation), yaitu pempimpin merangsang pengikut untuk bersikap kreatif dan inovatif serta merangsang keyakinan dan nilai mereka sendiri, seperti nilai dan keyakinan

7 Sudarwan Danim dan Suparno, Manajemen Kepemimpinan Transformasional Ke Kepalasekolahan, (Jakarta: PT. RinekaCipta, 2009), 62.

8 Shalahuddin, Karakteristik Kepemimpinan Transformasional, h. 49. 
pemimpin serta organisasi. Jenis kepemimpinan ini mendukung pengikut ketika mencoba pendekatan baru dan mengembangkan cara inovatif untuk menghadapi masalah organisasi. Hal itu mendorong karyawan untuk memikirkan hal-hal secara mandiri dan terlibat dalam pengambilan keputusan yang hati-hati.

4. Pertimbangan yang diadaptasi (individualized consideration), yaitu pemimpin yang memberikan iklim yang mendukung dengan mendengarkan seksama kebutuhan masing-masing pengikut. Pemimpin bertindak sebagai pelatih dan penasehat serta mencoba untuk membantu pengikut dalam mewujudkan hal yang diinginkan.

Dalam tulisan ini, penulis memilih 1 karakter kepemimpinan transformasional yaitu inspirational motivation. Inspirational motivation adalah karakter seorang pemimpin yang mampu menerapkan standar yang tinggi, akan tetapi sekaligus mampu mendorong bawahan untuk mencapai standar tersebut. Karakter seperti ini mampu membangkitkan optimisme dan antusiasme yang tinggi dari para bawahan dengan senantiasa memberikan inspirasi dan memotivasi bawahannya.

Dalam beberapa tahun terakhir ini, robotika muncul sebagai kajian interdisipliner, dengan project based learning yang diajarkan mayoritas pada mata pelajaran Sains, Matematika dan Teknologi dan memberikan manfaat bagi semua level pendidikan. ${ }^{9}$ Tujuan dari robotika dalam pendidikan sendiri adalah memungkinkan peserta didik untuk mengontrol pergerakan dari model nyata melalui lingkungan virtual. ${ }^{10}$ Melalui robotika, peserta didik dapat membangun sesuatu dengan sendirinya seperti benda nyata dan peserta didik bisa menyentuh langsung benda tersebut untuk menemukan konsep pembelajaran. ${ }^{11}$

SMA Averos merupakan Sekolah Menengah Atas yang mengedapankan Ilmu Pengetahuan dan Teknologi (IPTEK) dalam pembelajarannya. SMA

\footnotetext{
9 Alimisis, D., \& Moro, M. (n.d.), Roboticse Constructivism in Education, the TERECoP project, 2010, 1-11.

${ }^{10}$ Alimisis, D. Robotics in Education \& Education in Robotics, Shifting Focus from Technology to Pedagogy, 2012, h. 7-14.

${ }^{11}$ Ibid.
} 
Averos merupakan Sekolah Menegah Atas di bawah Yayasan Sains Averos. SMA Averos atau juga disebut Sains Averos merupakan salah satu sekolah menengah atas swasta yang terletak di jalan Dominggus Edward Osok Km. 12 Masuk Kota Sorong, Provinsi Papua Barat. SMA Averos merupakan sekolah yang pertama mendirikan program khusus di bidang Sains di Kota Sorong. Sekolah ini hanya memiliki satu jurusan yaitu Jurusan Ilmu Pengetahuan Alam (IPA). Mata pelajaran Sains meliputi Biologi, Kimia, Fisika, Matematika, Astronomi, dan Robotika. Mata pelajaran Robotika merupakan mata pelajaran unggulan di SMA Averos. Selain mata pelajaran, Robotika juga menjadi kegiatan ekstrakurikuler bagi siswa SMA Averos.

Pembelajaran robotika bagi siswa SMA Averos merupakan pelajaran muatan lokal dan robot-robot hasil karya siswa SMA Averos yang sudah pernah dipamerkan diantaranya robot Wall Follower, Arduino Linetracer, Hexpod, Cuad Copter. Dalam pembelajaran robotik, siswa diajari dan dilatih menciptakan robot, agar siswa lebih gesit dan cekatan dalam mendesain dan merakit sirkuit, mengembangkan logika serta menambah wawasan dasar-dasar elektronika. ${ }^{12}$

Salah satu bentuk prestasi yang dicapai oleh siswa SMA Sains Averos yaitu: Gonselves CJ Bungalolon (17), Siswa SMA Averos Kota Sorong mendapat beasiswa di Universitas Fladovick Moskow, Rusia. Meskipun harus bergelut di bidang yang beresiko tinggi, Gonselves tetap bersikukuh untuk mengambil jurusan tekhnik nuklir di Rusia. Ia berkeinginan untuk memajukan Indonesia di bidang militer. ${ }^{13}$ Banyak prestasi yang telah diraih oleh SMA Averos, diantaranya adalah juara lomba olimpiade sains, dan bisa meraih juara di tingkat nasional dan ada juga yang dikirim bertanding ke luar negeri. ${ }^{14}$

${ }^{12}$ Anis Nurul Hikmah, Guru Bahasa Inggris SMA Averos Kota Sorong, Wawancara, 10 Desember 2018.

${ }^{13}$ Anis Nurul Hikmah, Guru Bahasa Inggris SMA Averos Kota Sorong, Wawancara, 10 Desember 2018.

${ }^{14}$ Anis Nurul Hikmah, Guru Bahasa Inggris SMA Averos Kota Sorong, Wawancara, 10 Desember 2018. 
Berdasar pada hal tersebut di atas, penulis tertarik untuk membahas gaya kepemimpinan inspirational motivation Kepala Sekolah dalam pembelajaran sains robotika di SMA Averos Kota Sorong.

\section{Pembelajaran Sains Robotika di SMA Averos Kota Sorong}

SMA Averos Kota Sorong didirikan pada tahun 2007, namun pembelajaran sains robotika baru diajarkan pada tahun ajaran 2010/2011 di SMA Averos Kota Sorong. Jadi butuh waktu sekitar 3 tahun, SMA Averos Kota Sorong untuk memulai pembelajaran sains robotika. Hal yang mendasari pembelajaran sains robotika dilakukan di SMA Averos adalah untuk meningkatkan kualitas peserta didik SMA Averos agar ketika lulus kelak memiliki daya saing di era yang menitikberatkan perkembangan sains dan teknologi. ${ }^{15}$ Dalam perkembangannya, siswa diajari dan dilatih menciptakan robot agar siswa lebih gesit dan cekatan dalam mendesain dan merakit sirkuit, mengembangkan logika, dan menambah wawasan dasar-dasar elektronika. ${ }^{16}$

Keterampilan siswa dalam merakit robot sebagai bentuk penguasaan materi pelajaran sekolah di bidang pembelajaran sains, khususnya pelajaran matematika, kimia, fisika, astronomi, dan robotika itu sendiri. Tujuan pembelajaran sains bagi siswa bukan hanya untuk meningkatkan pengetahuan dan keterampilan siswa saja, akan tetapi juga untuk menumbuhkembangkan sikap positif terhadap sains itu sendiri maupun di lingkungannya serta menerapkan dan menghubungkannya dalam kehidupan sehari-hari secara lebih aktif dan efektif.

SMA Averos Kota Sorong menggunakan kurikulum robotika dengan mengacu dan mengadopsi dari Institut Teknologi Sepuluh Nopember (ITS), karena mata pelajaran sains robotika belum tercantum dalam kurikulum nasional sehingga seluruh perangkat pembelajarannya, mulai silabus, Rencana Pelaksanaan Pembelajaran (RPP) hingga bahan ajarnya

\footnotetext{
${ }^{15}$ Imam Wahudi, Kepala SMA Averos Kota Sorong, Wawancara, 9 Januari 2019.

${ }^{16}$ David Piter Raymond Luhukay, Guru Matematika dan Robotika SMA Averos Kota Sorong, Wawancara, 9 Januari 2019.
} 
disusun oleh guru robotika sendiri. ${ }^{17}$ Guru robotika SMA Averos berjumlah 2 orang, yaitu Bapak David Piter Raymond Luhukay dan Bapak Bagus Dwi Kurniawan. ${ }^{18}$ Kedua guru tersebut kompeten dalam bidangnya dan pihak sekolah rutin mengirim guru tersebut untuk terus memperdalam ilmunya di ITS agar update dengan informasi terkait perkembangan robotik.

Dalam pengembangan kurikulum robotika, SMA Averos Kota Sorong bekerja sama dengan Himpunan Mahasiswa Jurusan Institut Teknologi Sepuluh Nopember (HMJ ITS) dan Tim R-Plane (Tim Pengembangan Robotik Surabaya), serta disesuaikan dengan tingkat kemampuan siswa di kelas dalam menyerap materi. Kurikulum robotika SMA Averos dikembangkan dengan berbasis projek dan inovantion (penemuan). ${ }^{19}$

Robotikadi SMA Averos Kota Sorong merupakan mata pelajaran muatan lokal (mulok). Robotika terbagi dua, yaitu robotika sebagai mata pelajaran (mapel) dan robotika club. Pelajaran sains robotika diberikan kepada siswa Kelas X dan Kelas XI SMA Averos Kota Sorong.

Pembelajaran sains robotika pada kelas X merupakan pembelajaran dasar robotika. Dengan pembelajaran tersebut, siswa memahami asal usul robotik dan kecerdasan buatan manusia serta siswa mampu membuat cirkuit board robot dan mikrokontroler. Adapun waktu yang dibutuhkan dalam pembelajaran tersebut adalah 70 Jam Pelajaran (JPL). Karakter yang diharapkan dalam pembelajaran sains robotika adalah kreatif, kerja keras, rasa ingin tahu, dan disiplin siswa.

Pembelajaran sains robotika pada kelas XI merupakan pembelajaran inti dalam robotik. Dalam pembelajaran ini, siswa memahami Pemrogaman $\mathrm{C}++$ pada mikrokontroler, perkembangan dan pemanfaatannya sensor pada arduino, servo dan motor dc, Proyek LCD dan membuat robot sederhana yang melibatkan sensor. Waktu yang dibutuhkan dalam pembelajaran tersebut adalah 82 JPL. Dan Karakter yang diharapkan dalam pembelajaran sains robotika adalah kreatif, kerja keras, rasa ingin tahu, dan disiplin siswa.

\footnotetext{
${ }^{17}$ Imam Wahudi, Kepala SMA Averos Kota Sorong, Wawancara, 9 Januari 2019.

${ }^{18}$ Imam Wahudi, Kepala SMA Averos Kota Sorong, Wawancara, 9 Januari 2019.

${ }^{19}$ David Piter Raymond Luhukay, Guru Matematika dan Robotika SMA Averos Kota Sorong, Wawancara, 9 Januari 2019.
} 
Tahun Ajaran 2018/2019, Jadwal Pelajaran Sains Robotika SMA Averos Kota Sorong ${ }^{20}$ dapat dilihat pada tabel berikut:

\begin{tabular}{|c|c|c|c|}
\hline Hari & Jam Pelajaran & Kelas & Tempat \\
\hline Senin & $12.00-13.30$ & XI A & Ruang Robotik \\
\hline \multirow{2}{*}{ Selasa } & $08.30-10.00$ & XI C & Ruang Robotik \\
\cline { 2 - 4 } & $12.00-13.30$ & X B & Ruang Robotik \\
\hline Rabu & $07.30-8.30$ & X A & Ruang Robotik \\
\hline Kamis & $12.00-13.30$ & X C & Ruang Robotik \\
\hline Jumat & - & - & - \\
\hline Sabtu & $10.30-12.00$ & XI B & Ruang Robotik \\
\hline
\end{tabular}

Berdasarkan jadwal tersebut di atas, pembelajaran robotik hanya satu kali pertemuan untuk setiap kelas, baik kelas X maupun kelas XI yang dilaksanakan di ruangan robotik dan waktu yang digunakan adalah 2 JPL (1 Jam 30 Menit).

Selain pembelajaran sains robotik sebagai mata pelajaran muatan lokal di kelas, SMA Averos juga memberikan pembelajaran sains robotik dalam bentuk robotika club. Robotika club merupakan kegiatan ekstrakurikuler yang diajarkan di luar jam pelajaran. ${ }^{21}$ Robotika club merupakan kegiatan ekstrakurikuler agar anak-anak dapat mempelajarinya dengan baik dan waktunya bisa tersedia lebih banyak karena dalam pembelajaran robotika sebagai mulok yang diajarkan hanya 2 jam pelajaran, tentu waktunya tidak cukup banyak untuk mempelajarinya. ${ }^{22}$

Dalam robotika club, tidak semua siswa kelas X dan XI ikut dalam pembelajaran tersebut sebagaimana pembelajaran robotik sebagai mulok di kelas. Jadi siswa yang ikut dalam robotik club adalah siswa yang memang ingin menekuni dan mengembangkan pengetahuan robotiknya.

${ }^{20}$ Fitra Awalia, Wakil Kepala Sekolah SMA Averos Kota Sorong, Wawancara, 12 Januari 2019.

${ }^{21}$ Chyanida Ferry Saputra, Guru Bahasa Inggris SMA Averos Kota Sorong, Wawancara, 8 Januari 2019.

${ }^{22}$ Fitra Awalia, Wakil Kepala Sekolah SMA Averos Kota Sorong, Wawancara, 12 Januari 2019. 
Dari jumlah siswa 197 orang Kelas X dan XI, hanya 17 orang siswa yang ikut dalam robotik club, 9 orang siswa Kelas X dan 8 orang siswa kelas XI. Adapun nama-nama siswa tersebut adalah sebagai berikut:

\begin{tabular}{|c|l|c|}
\hline No & Nama & Kelas \\
\hline 1 & Alica Kirana & Kelas X \\
\hline 2 & Wahyudha & Kelas X \\
\hline 3 & Luthfi & Kelas X \\
\hline 4 & Inyoman & Kelas X \\
\hline 5 & Astagina Pramesty & Kelas X \\
\hline 6 & Alfiq & Kelas X \\
\hline 7 & Zakaria Rabbani & Kelas X \\
\hline 8 & Ali Fikri & Kelas X \\
\hline 9 & Teguh & Kelas X \\
\hline 10 & Rizki Pratama & Kelas XI \\
\hline 11 & Rayhan Najib & Kelas XI \\
\hline 12 & Jeremi Sitanggang & Kelas XI \\
\hline 13 & Ipul Ersya & Kelas XI \\
\hline 14 & Abi Adzgifari & Kelas XI \\
\hline 15 & Ralphy & Kelas XI \\
\hline 16 & Nanda & Kelas XI \\
\hline 17 & Free Young & Kelas XI \\
\hline
\end{tabular}

Secara umum, Sistem pembelajaran yang digunakan SMA Averos selama ini adalah sistem paket, tak terkecuali pembelajaran robotik. Siswa akan selesai secara bersama-sama, karena masuknya sama-sama sehingga lulusnya pun sama-sama. Jadi siswa yang cepat belajarnya akan direm sedikit kecepatannya dan siswa yang lambat akan dipacu sehingga bisa bersama-sama dalam ujian dan lulus bersama-sama. Untuk tahun 2019/2020, SMA Averos akan berlakukan sistem SKS atau akselerasi. Sistem SKS ini disesuaikan dengan kecepatan masing-masing siswa. Siswa 
yang cerdas bisa selesai hanya dengan 2 tahun, sedangkan siswa yang lambat bisa 3 tahun dan bahkan 4 tahun selesai. Hal tersebut dapat dilihat pada hasil ujian nasional, siswa yang cerdas nilainya mencapai 94 dan siswa yang kurang cerdas nilainya 50, bahkan ada nilai 35. Interval perolehan tersebut jauh sekali sehingga dengan sistem SKS dapat memotivasi siswa dan berpacu dalam belajar. Dalam pembelajaran dengan sistem SKS, siswa yang kurang cerdas akan lebih diperhatikan agar ada keseimbangan antara anak yang cerdas dan anak yang kurang cerdas. ${ }^{23}$

Dalam menangani anak yang kurang cerdas, guru mempersiapkan diri untuk selalu memberikan motivasi kepada siswa agar mereka memiliki keinginan untuk selalu belajar. Guru SMA Averos Kota Sorong adalah guru-guru yang cerdas dan rata-rata memiliki nilai cumlaude, memiliki latar belakang kompetensi yang sangat baik, masih muda dan bekerja dengan penuh semangat, memiliki dedikasi yang tinggi, dan mau bekerja dengan sungguh-sungguh demi kemajuan anak-anak serta mau bersamasama menuju pencapaian visi dan misi sekolah. ${ }^{24}$

Dalam pembelajaran sains robotik, SMA Averos telah menyediakan seluruh fasilitas pembelajaran robotik, mulai laboratorium, peralatan (solder, multimeter), hingga pelatihan rutin untuk guru pengampu robotik. ${ }^{25}$ Fasilitas pembelajaran robotik di SMA Averos telah memenuhi standar kebutuhan, pengembangan dan pembangunan projek, meliputi: alat desain dan cetak board robot, laboratorium komputer untuk pengembangan program, alat perakitan (solder dan perkakas), dan rak penyimpanan stok komponen. ${ }^{26}$ Walaupun fasilitasnya sudah memadai, namun masih terdapat kendala dalam pembelajaran robotik, yaitu ketersediaan komponen pendukung di Kota Sorong. ${ }^{27}$ Terbatasnya ketersediaan komponen di Kota Sorong sehingga harus pesan dulu dari Surabaya yang membutuhkan waktu dan biaya pengiriman.

\footnotetext{
${ }^{23}$ Imam Wahudi, Kepala SMA Averos Kota Sorong, Wawancara, 9 Januari 2019.

${ }^{24}$ Imam Wahudi, Kepala SMA Averos Kota Sorong, Wawancara, 9 Januari 2019.

${ }^{25}$ Imam Wahudi, Kepala SMA Averos Kota Sorong, Wawancara, 9 Januari 2019.
}

26 David Piter Raymond Luhukay, Guru Matematika dan Robotika SMA Averos Kota Sorong, Wawancara, 24 Januari 2019.

${ }^{27}$ Imam Wahudi, Kepala SMA Averos Kota Sorong, Wawancara, 9 Januari 2019. 
Siswa SMA Averos Kota Sorong memiliki minat yang tinggi dalam mempelajari dan mengembangkan robotik. Hal yang mempengaruhi minat siswa dalam pembelajaran robotik tersebut adalah karya-karya yang pernah dibuat oleh kakak kelas maupun alumni, prestasi dan pengalaman kompetisi robot yang pernah dialami oleh kakak kelas dan alumni, banyaknya contoh-contoh dan tutorial pengembangan robot yang dapat mereka lakukan sendiri, dan penggunaan microprosesor arduino sebagai media pembelajaran dan pengembangan robotik yang mudah untuk dipelajari dan dirakit oleh siswa. ${ }^{28}$ Selain itu, mayoritas siswa masuk SMA Averos karena adanya pelajaran robotik dan tidak ada sekolah lain yang menerapkan pelajaran tersebut. ${ }^{29}$

Pada tahun 2018, pembuatan robot di SMA Averos terdiri dari 7 tim yang masing-masing beranggotakan 3 orang. Robot-robot yang berhasil dibuat adalah robot yang mempunyai 2 komponen dasar, yaitu komponen elektronika dan prosesor. Robot Arduino Linetracer adalah salah satu robot yang pernah dilombakan di Institut Teknologi Surabaya (ITS) tahun 2017 dan SMA Averos merupakan satu-satunya perwakilan dari Provinsi Papua Barat. Dalam lomba tersebut diikuti oleh 80 tim robot dari seluruh Indonesia dan SMA Averos lolos sampai perempat final.

Sehubungan dengan pembelajaran robotik di SMA Averos Kota Sorong, Kepala Sekolah SMA Averos berharap pembelajaran robotik di SMA Averos Kota Sorong diharapkan tidak berhenti sampai disini saja, melainkan terus berkembang mengikuti teknologi terbarukan dan semakin banyaknya inovasi pengembangan pembelajaran robotik dari karya peserta didik SMA Averos. ${ }^{30}$

${ }^{28}$ David Piter Raymond Luhukay, Guru Matematika dan Robotika SMA Averos Kota Sorong, Wawancara, 24 Januari 2019.

${ }^{29}$ Imam Wahudi, Kepala SMA Averos Kota Sorong, Wawancara, 9 Januari 2019.

${ }^{30}$ Imam Wahudi, Kepala SMA Averos Kota Sorong, Wawancara, 9 Januari 2019. 


\section{Kepemimpinan Inspirational Motivation Kepala Sekolah dalam Pembelajaran Sains Robotika di SMA Averos Kota Sorong}

Dalam pembelajaran sains robotika di SMA Averos Kota Sorong, Kepala SMA Averos Kota Sorong cukup banyak memberikan dukungan dan perhatian, baik secara moril maupun dana. Kepala SMA Averos Kota Sorong selalu memberikan dukungan dalam persiapan maupun pengembangan robotik untuk diikutsertakan dalam lomba dan memberikan apresiasi dorongan moril serta dana untuk meningkatkan kemampuan guru dalam pembelajaran.

Kepala SMA Averos Kota Sorong bersikap tegas, disiplin, bertanggungjawab, dan bekerjasama dalam pembelajaran sains robotika. Dalam menanamkan kedisiplinan, Kepala SMA Averos memberikan ikatan/ perjanjian bagi guru. Setiap tahun guru dibuatkan SK, dan bagi guru yang layak untuk mengajar serta dianggap memiliki dedikasi tinggi dalam mengajar akan di SK kan kembali mulai Juli sampai Juni. Jika dalam perjalanannya ada guru yang tidak mampu mengikuti aturan kedisiplinan sekolah, maka bisa jadi tiga atau enam bulan saja mengajar di SMA Averos dan selebihnya dikeluarkan. ${ }^{31}$

Salah satu motivasi kepala sekolah kepada guru-gurunya adalah memperhatikan kesejahteraan mereka dengan memberikan honor yang hampir setara dengan PNS, menyiapkan asrama tempat tinggal bagi guru yang rumahnya jauh dari Kota Sorong seperti daerah Jawa, dan menyiapkan sarana dan prasarana yang lengkap sesuai dengan kebutuhan guru. ${ }^{32}$ Selain itu, kepala sekolah juga memberikan reward dan insentif para personil sekolah termasuk guru, partisipasi (pemberdayaan) guru, pendelegasian wewenang, dan menciptakan hubungan yang harmonis serta memberikan contoh teladan kepada guru.

Bagi siswa, kepala sekolah memberikan motivasi dengan memberikan fasilitasi kepada siswa yang berprestasi untuk mengikuti lomba dan

\footnotetext{
${ }^{31}$ Imam Wahudi, Kepala SMA Averos Kota Sorong, Wawancara, 9 Januari 2019.

${ }^{32}$ Imam Wahudi, Kepala SMA Averos Kota Sorong, Wawancara, 9 Januari 2019.
} 
sekolah membiayai semua kegiatan itu. Dan setiap tahun di bulan Januari, SMA Averos mengadakan pameran sains di sekolah dengan menampilkan semua hasil karya siswa.

Dalam bekerja, Kepala Sekolah SMA Averos selalu melibatkan seluruh bawahannya sesuai dengan job description dari masing-masing anggotanya. Misalnya, kepala sekolah memprogramkan pameran sains di sekolah bagi siswa. Kepala sekolah menyampaikan keinginannya kepada seluruh guru dan stafnya melalui rapat dewan guru dan staf sehingga kepala sekolah menjadi sumber inspirasi bagi bawahannya. Semua guru, tenaga administrasi, siswa dan orang tua siswa berperan aktif untuk menyukseskan pameran tersebut. ${ }^{33}$

Imam Wahyudi selaku kepala sekolah juga memberikan apresiasi kepada guru-guru yang telah melaksanakan tugasnya dengan baik dan terhadap siswa yang berprestasi. Pemberian apresiasi ini merupakan bentuk reward yang sangat penting sebagai bentuk penghargaan bagi bawahannya di sekolah. ${ }^{34}$

Enam bulan sebelum dilakukan pameran, siswa telah mempersiapkan dirinya dengan membuat karya-karya yang bisa ditampilkan di pameran. Dengan adanya pameran sains tersebut membuat siswa untuk selalu berfikir dan kreatif menciptakan suatu karya di bidang sains. Siswa-siswi sangat senang dengan adanya pameran tersebut, karena karya-karya mereka dapat dilihat oleh siswa-siswi yang lain, bahkan sekolah-sekolah dari luarpun berdatangan melihat karya-karya mereka.

SMA Averos pada tahun 2018 telah melakukan pameran di sekolah dengan menampilkan stand-stand pelajaran sains, seperti stand biologi, fisika, kimia, astronomi, dan robotika. Yang paling banyak menarik pengunjung adalah stand robotika yang menampilkan karya-karya siswa SMA Averos yang diantaranya pernah diikutkan dalam lomba robotika tingkat nasional, yaitu robot Wall Follower, Arduino Linetracer, Hexpod, dan Cuad Copter. Tujuan dari pameran robot ini adalah untuk membuat siswa SMA

${ }^{33}$ Fitrah Awalia, Guru Kimia dan Wakil Kepala Sekolah SMA Averos Kota Sorong, Wawancara 10 Mei 2019.

${ }^{34}$ Fitrah Awalia, Guru Kimia dan Wakil Kepala Sekolah SMA Averos Kota Sorong, Wawancara 10 Mei 2019. 
Averos memiliki semangat dalam mengembangkan kemampuan mereka ke tingkat yang lebih inovatif dan menciptakan robot yang lebih cerdas serta semua orang yang datang agar tidak takut terhadap sains, namun sebaliknya sains itu asyik.

Pelajaran sains robotika di SMA Averos meurut Ratna, salah seorang siswi SMP dan pengunjung pameran sains Averos Kota Sorong, mengatakan bahwa "SMA Sains Averos ini merupakan salah satu sekolah unggulan di Papua Barat yang kualitasnya sangat baik. Anak-anaknya bisa menciptakan robot sendiri, bermain-main dengan ilmu sains, membuka wawasan dan logika kita sehingga kita bisa berlatih dan tidak ketinggalan dengan siswa-siswa lain di Jawa maupun luar negeri." ${ }^{35}$

Keterampilan siswa SMA Averos Kota Sorong dalam merakit robot melalui pelajaran sains robotika sehingga memperoleh prestasi di tingkat lokal, nasional dan bahkan interansional (olimpiade) tidak terlepas dari kepemimpinan kepala SMA Averos Kota Sorong yang selalu memberikan dorongan, dukungan dan memotivasi siswa untuk terus berkarya dan berprestasi. Secara teoritis, kepemimpinan kepala SMA Averos telah melakukan transformative terhadap perilaku, ketaatan dan disiplin siswa dalam mengembangkan bakat dan minat robotika.

Sementara itu, dalam teori inspirational motivation menunjukkan bahwa sikap dan perilaku kepemimpinan kepala SMA Averos Kota Sorong merupakan seorang yang mampu memotivasi bawahannya untuk selalu terus berkarya, bekerjasama dan mampu melaksanakan tugasnya sesuai dengan job description masing-masing bawahannya sehingga disaat terjadi kelesuan atau kondisi down guru, staf dan siswa, maka kepala sekolah mampu memberikan semangat dan cara memberikan reward dan punishment. Kemudian berkat dukungan penuh dan inspirational motivation kepala SMA Averos Kota Sorong kepada seluruh siswanya dalam merakit robot, maka banyak siswa SMA Averos mencapai prestasi gemilang di tingkat nasional maupun interansional.

${ }^{35}$ Pameran Sains Robotika Di SMA Averos Kota Sorong.Lihat di https://kezyaratu30. wordperss.Com/2018/05/14/pameran-sains-di-sma-averos. Diakses pada tanggal 9 November 2018. 


\section{Output Siswa dalam Pembelajaran Sains Robotika di SMA Averos Kota Sorong}

Sejak mulai berdirinya hingga sekarang, siswa SMA Averos telah mampu menghasilkan beberapa karya robotik sebagai berikut:

1. Robot Soccer - Transforter Arduino

Robot soccer adalah robot yang digunakan untuk hiburan dalam bermain bola antar robot. Robot ini dibuat oleh siswa anggota robotik tahun 2013.

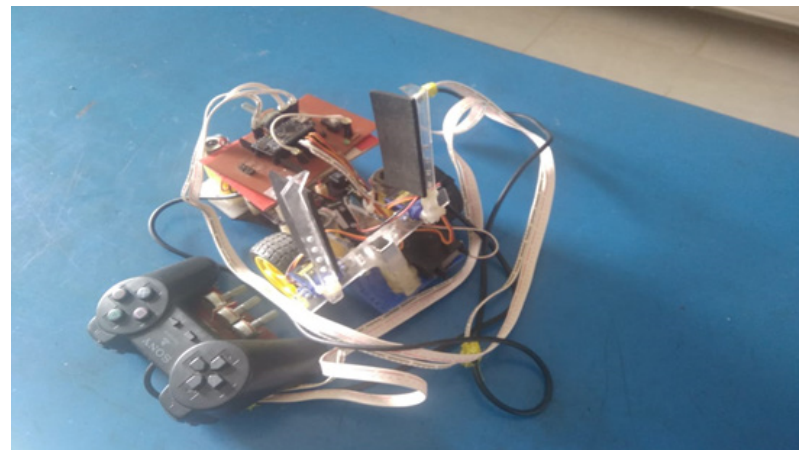

2. Drone

Robot ini dibuat oleh siswa anggota robotik tahun 2013.

3. Robot Linetracer Analog 12 Sensor

Robot linetracer adalah robot yang mengikuti garis hitam sesuai lintasan. Robot ini dibuat oleh siswa anggota robotik tahun 2014. Berikut adalah robot linetracer berbasis arduino:

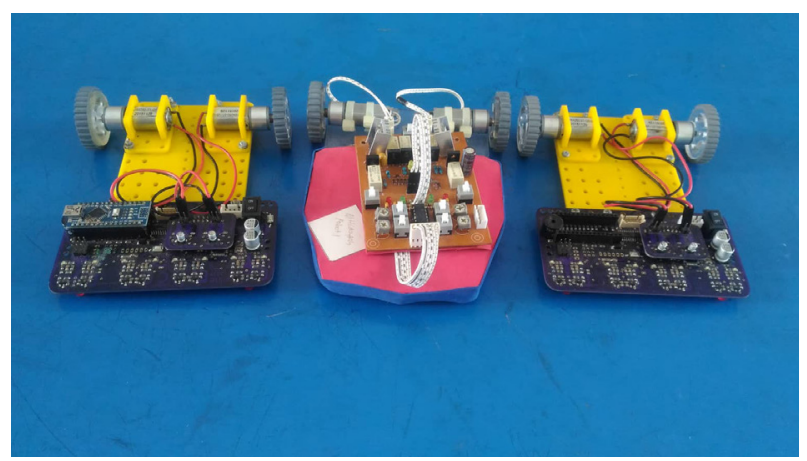


4. Robot Wall Follower

Robot wall follower adalah robot yang bisa bergerak tanpa menabrak benda di sekitarnya. Robot ini dibuat oleh siswa anggota robotik tahun 2014.

5. Robot Transforter Analog

Robot transporter adalah robot yang bisa memindahkan barang dari satu tempat ke tempat lain dengan kendali joystick. Berikut adalah robot transporter:
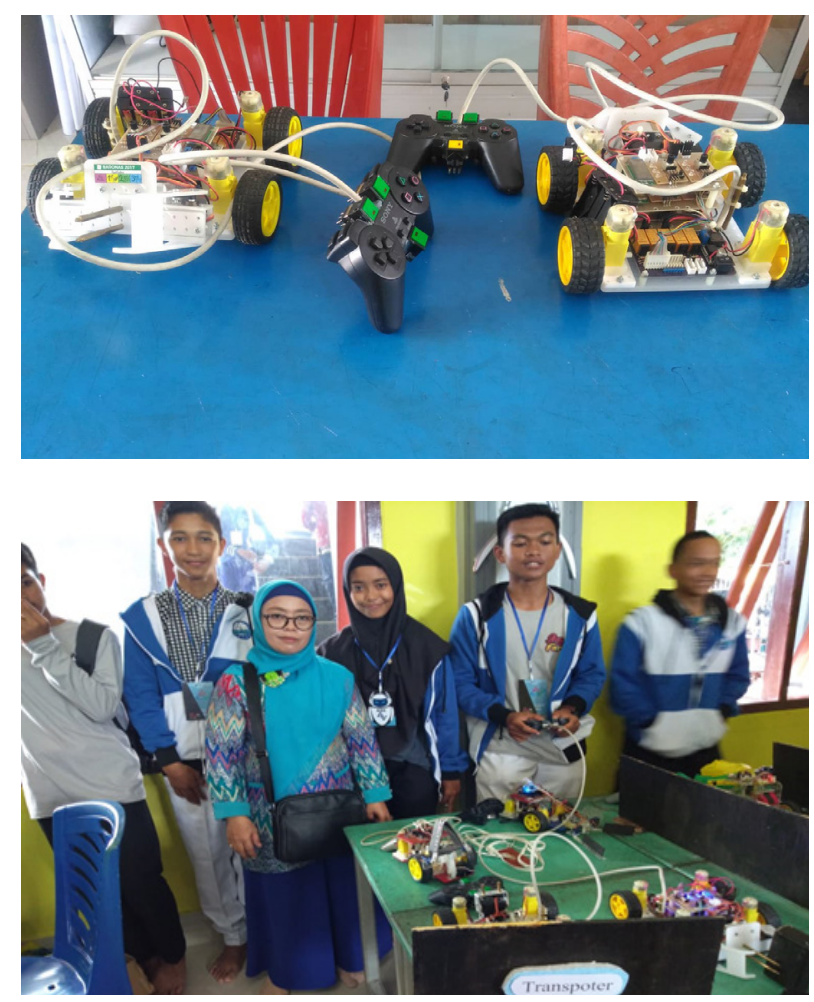

Pameran SMA Averos Kota Sorong, Januari 2019

6. Miniatur Rumah Berbasis Wireles Bluetooth

Miniatur rumah IOT adalah menampilkan miniatur rumah yang dikendalikan melalui smartphone. Robot ini dibuat oleh luthfi tahun 2018. 


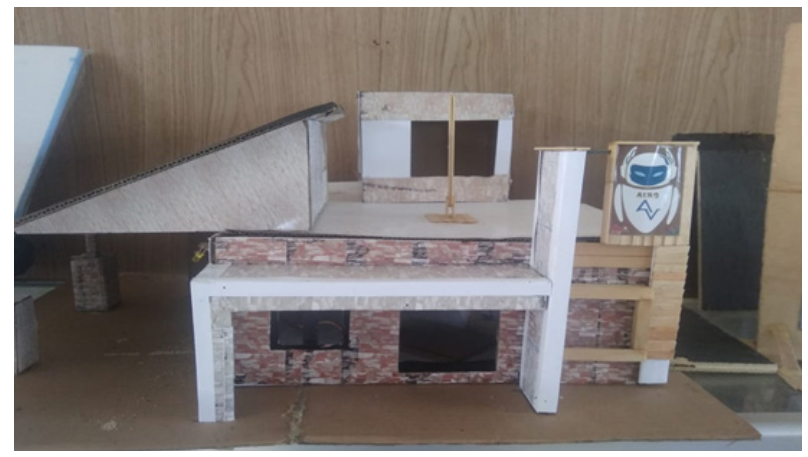

7. Alingu

Alingu adalah alat bantu komunikasi untuk tunarungu. Alingu dibuat oleh Rozi tahun 2018. Berikut adalah Jam Tangan Alat Bantu Tuna Rungu Berbasis Arduino dengan Kontrol Smarphone:

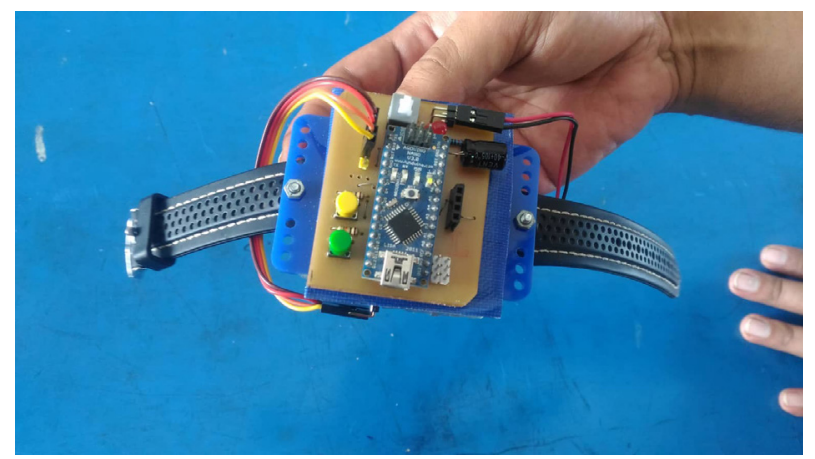

8. Seven Segmen

Seven segmen adalah penampil angka, seperti papan skor lapangan sepak bola. Seven segmen dibuat oleh Rayhan, Nanda, dan Jeremy tahun 2018.

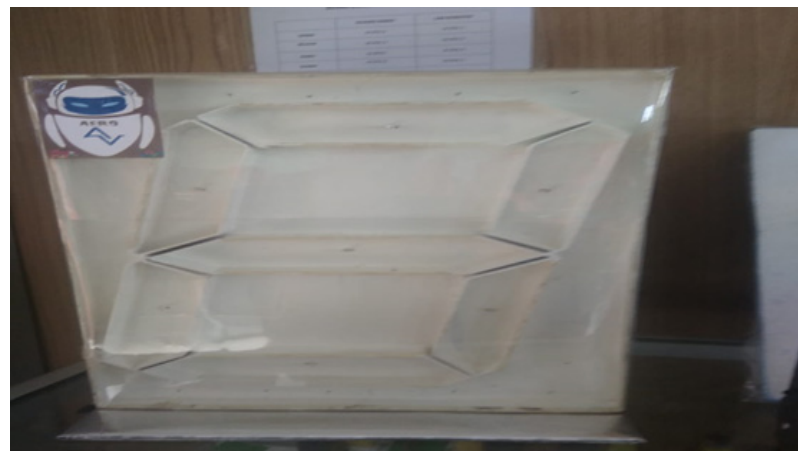


9. Robot Pairing Bluetooth

Robot Pairing Bluetooth adalah robot yang mempelajari pairing bluetooth dan sensor flekx (sensor gerak). Robot ini dibuat oleh Rizky Raihan Najib dan Rizky Pratama. Berikut adalah Robot Pairing Bluetooth yang ditampilkan dalam pameran SMA Averos bulan januari tahun 2019:

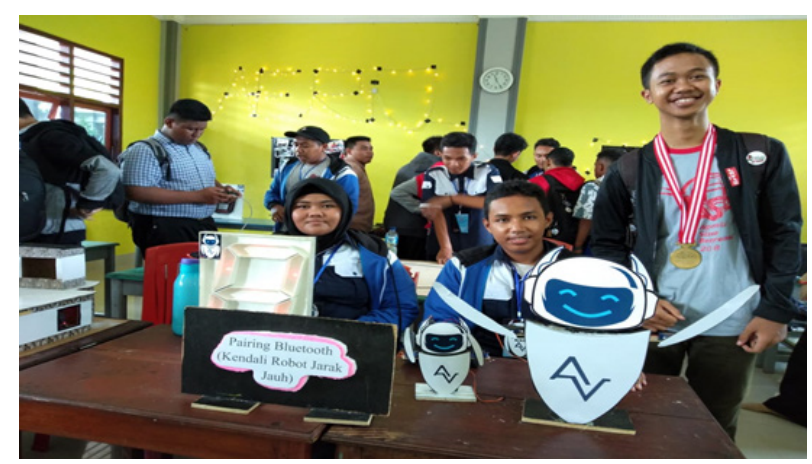

Dari beberapa karya robotik di atas, siswa SMA Averos mendapatkan prestasi sebagai berikut:

1. Peraih medali emas di OPSI (Olimpiade Penelitian Siswa Indonesia) Tahun 2018

2. Finalis IYSIF (International Youth Science and Inovation Fair) Tahun 2018

3. Wakil Indonesia dalam Intel ISEF 2019 di Arizona, Amerika Serikat 4. 16 Besar BARONAS (Lomba Robot Nasional) Tahun 2016 di Surabaya 5. Peserta BARONAS (Lomba Robot Nasional) Tahun 2015, 2016, 2017 6. Karya Ilmiah Siswa: Aplikasi E-Tilang, Robot Peramal Cuaca, Robot Pengukur Tinggi Gedung (Media Pembelajaran). ${ }^{36}$

Selain itu, prestasi siswa SMA Averos secara perorangan adalah sebagai berikut:

1. Rayhan

a. Juara 1 Lomba Cerdas Cermat Tingkat Gugus Kota

b. Juara 1 Tingkat Kota dan Provinsi MTQ

${ }^{36}$ Imam Wahudi, Kepala SMA Averos Kota Sorong, Wawancara, 9 Januari 2019. 
c. Kelompok Terbaik Peserta Perkemahan Ilmiah Remaja Nasional - LIPI

d. Juara 2 Lomba Peneliti Belia

2. Nanda. Peserta Indonesia Science Project Olympiad tahun 2019

3. Ralphy. Peserta Indonesia Science Project Olympiad tahun 2019

4. Ipul Ersya
a. Lomba MIPA Tingkat Kota (SD)
b. Loop Kita Membuta Video Teaser Tingkat SMA
c. Peserta Lomba LKAS 2019
d. Lomba Matematika Tingkat Kabupaten (SD)
e. Juara 1 Paduan Suara Tingkat Sekolah Averos
f. Peserta Lomba Mobile Legends Kota Sorong (Telkomsel)

5. Abi Adzghifari
a. Peserta Lomba Video Loop Competition
b. Peserta Lomba Rap Kemalpahlevi
c. Juara 1, 3, dan Best Race Tamiya Speed Nascar Jayapura
d. Juara 2 Lomba Mobil Legend di Mooi Park Sorong
e. Juara 2 Lomba Mobile Legend di Kopi Item
f. Juara 1 Tamiya di Alun-alun Aimas
g. Peserta Lomba Tenis Meja se Kota Sorong dalam rangka HUT SIT Al-Izzah

6. Alfiq Ibrahim Aji
a. Juara 2 OSP Tingkat SD
b. Juara 2 MTQ Tingkat Provinsi Bidang Fahm Qur'an
c. Juara 2 Menembak Kapolres Cup Tingkat Pelajar Kota
d. Juara 2 Menembak Tingkat Pelajar Antar Club (PERBAKIN)

Untuk lulusan siswa SMA Averos, 18 siswa SMA Averos tahun 2016 lolos kuliah ke luar negeri dan beasiswa dari kedutaan besar Rusia, China, Jerman dan Australia. Gonsalves lolos ke Rusia dengan mengambil jurusan nuklir. Gonsalves merupakan orang pertama dari Papua Barat yang lolos ke Rusia. Gonsalves adalah salah satu dari delapan siswa Indonesia yang 
lolos ke Rusia. Selanjutnya, 2 siswa ke Australia, 11 siswa ke China, dan 4 siswa ke Jerman.

\section{Penutup}

Berdasarkan uraian di atas, maka kesimpulan dalam tulisan ini adalah sebagai berikut:

1. Pembelajaran sains robotika pertama kali diajarkan pada tahun ajaran 2010/2011 di SMA Averos Kota Sorong. Sains Robotika merupakan mata pelajaran muatan lokal (mulok) di SMA Averos Kota Sorong. Tujuan pembelajaran sains robotika adalah untuk meningkatkan kualitas peserta didik SMA Averos agar ketika lulus kelak memiliki daya saing di era yang menitikberatkan perkembangan sains dan teknologi. Kurikulum robotika SMA Averos adalah kurikulum yang mengacu dan mengadopsi dari Institut Teknologi Sepuluh Nopember (ITS). Dan dalam pengembangan Kurikulum robotika, SMA Averos Kota Sorong bekerjasama dengan Himpunan Mahasiswa Jurusan Institut Teknologi Sepuluh NOPEMBER (HMJ ITS) dan Tim R-Plane (Tim Pengembangan Robotik Surabaya), serta disesuaikan dengan tingkat kemampuan siswa di kelas dalam menyerap materi.

2. Kepemimpinan Inspirational Motivation Kepala Sekolah dalam Pembelajaran Sains Robotika di SMA Averos Kota Sorong adalah kepedulian pada guru, staf dan siswa, melibatkan semua orang, memberi penghargaan, memastikan pekerjaan itu menyenangkan, menunjukkan kepercayaan nyata, dan mendengarkan bawahan. Dan setiap tahun di bulan Januari, SMA Averos mengadakan pameran sains di sekolah dengan menampilkan semua hasil karya siswa. Berkat dukungan penuh dan inspirational motivation kepala SMA Averos Kota Sorong kepada guru dan siswanya dalam pembelajaran ssains robotika, maka banyak siswa SMA Averos mencapai prestasi gemilang di tingkat nasional dan internasional.

3. Output siswa dalam pembelajaran sains robotika di SMA Averos Kota Sorong adalah siswa mampu menciptakan robot, yaitu Robot Soccer - Transforter Arduino tahun 2013, Drone tahun 2013, Robot 
Linetracer Analog 12 Sensortahun 2014, Robot Wall Follower 2014, Robot Transforter Analog 2017, Miniatur Rumah Berbasis Wireless Bluetooth tahun 2018, Alingu tahun 2018, Seven Segmen tahun 2018, dan Robot Pairing Bluetooth.

Implikasi tulisan ini adalah sebagai berikut:

a. Kelengkapan peralatan pendukung menjadi hal yang perlu mendapat perhatian agar pembelajaran robotik bisa berjalan sesuai dengan yang diharapkan tanpa terkendala dengan alat yang masih harus dipesan dari luar Kota Sorong dan butuh waktu untuk pengadaannya sehingga pembelajaran sains robotika dapat lebih optimal di SMA Averos Kota Sorong.

b. Mengatur jadwal pembelajaran sains robotika siswa dalam robotik club secara rutin dalam setiap minggu untuk pengembangan sains robotika di SMA Averos Kota Sorong sehingga waktu belajar siswa bisa lebih banyak dan prestasi-prestasi siswa lebih banyak serta siswa yang mengikuti kegiatan robotik terus meningkat.

c. Mensosialisasikan kegiatan ekstrakurikuler robotik pada saat kegiatan masa orientasi siswa baru sehingga siswa baru yang memiliki kompetensi mempunyai gambaran tentang ekstrakurikuler tersebut dan timbul minat untuk mengikutinya.

\section{Daitar Pustaka}

Achua, Cristopher F. Effective Leadership, Canada: South-Western, 2010.

Bass, B.M.\& R.E. Riggio. Tranformational Leadership, New Jersey: Lawrence Erlbaum Associates, 2006.

Danim, Sudarwan dan Suparno. Manajemen Kepemimpinan Transformasional Ke Kepalasekolahan, Jakarta: PT. RinekaCipta, 2009.

D. Alimisis. \& Moro, M. (n.d.), Roboticse Constructivism in Education, the TERECoP project, 2010. 
D. Alimisis. Robotics in Education \& Education in Robotics, Shifting Focus from Technology to Pedagogy, 2012.

Guerrie, R. The Power of Effective Leadership in Schools, The BB \& T Leadership Institute, 2014.

Hay, I. Transformational Leadersiship: Characteristics and Criticism. School of Geography, Population and Enviromental Management Flinders University.Retrieved September 2016, from http://www. leadingtoday.org/weleadinlearning/transformationalleadership. htm.Guerrie, R. The Power of Effective Leadership in Schools, The BB \& T Leadership Institute, 2014.

Keith, S. \& R.H. Girling, Education, Management and Participation: New Direction In Educational. Administration. Mass: Adison Wesley Publishing Co, 1991.

Komariah, Aan dan Cepi Triatna.Visionary Ledership, Jakarta: Bumi Aksara, 2005.

Mustafa, Jejen. Kepemimpinan Kepala Sekolah, Dosen Fakultas Ilmu Tarbiyah dan Keguruan

Nawawi, Hadari. Kepemimpinan Menurut Islam, Yogyakarta: Gadjah Mada Pres, 2001.

Nawawi, Hadari. Kepemimpinan Yang Efektif, Cet. IV; Yogyakarta: Gajah Mada University Press, 2004.

Northouse, Peter G. Kepemimpinan: Teori dan Praktik, Cet. II; Jakarta: PT. Indeks, 2016.

Pameran Sains Robotika Di SMA Averos Kota Sorong.Lihat di https:// kezyaratu30.wordperss.Com/2018/05/14/pameran-sains-di-smaaveros. Diakses pada tanggal 9 November 2018. Pukul 12.30.WIT.

Shalahuddin. Karakteristik Kepemimpinan Transformasional, Al-Fikrah: Jurnal Kependidikan Islam, IAIN Sulthan Thaha Saifuddin, 2015.

Saebani, Beni Ahmaddan Li Sumantri, Kepemimpinan, Bandung: Pustaka Setia, 2014.

Wahab, Abdul Aziz.Anatomi Organisasi dan Kepemimpinan Pendidikan; Telaah terhadap Organisasi dan Pengelolaan Organisasi Pendidikkan,Bandung: Alfabeta, 2011. 
Wahjosumidjo. Kepemimpinan Kepala Sekolah: Tinjauan Teoretik dan Permasalahannya, Cet. VIII; Jakarta: PT RajaGrafindo Persada, 2011.

Wibowo. Kepemimpinan: Pemahaman Dasar, Pandangan Konvensional, Gagasan Kontemporer, Cet. II; Depok: Rajawali Pers, 2018. 
